\title{
Bleeding is the most common cause of unplanned return to operating room after lung cancer surgeries
}

\author{
Jiagen Li, Qi Xue, Yushun Gao, Yousheng Mao, Jun Zhao, Shugeng Gao \\ Department of Thoracic Surgery, National Cancer Center/National Clinical Research Center for Cancer/Cancer Hospital, Chinese Academy of \\ Medical Sciences and Peking Union Medical College, Beijing, China \\ Contributions: (I) Conception and design: J Li, J Zhao, S Gao; (II) Administrative support: S Gao; (III) Provision of study materials or patients: Q Xue, \\ Y Gao, Y Mao, J Zhao, S Gao; (IV) Collection and assembly of data: J Li; (V) Data analysis and interpretation: J Li, J Zhao; (VI) Manuscript writing: \\ All authors; (VII) Final approval of manuscript: All authors. \\ Correspondence to: Shugeng Gao, MD. Department of Thoracic Surgery, National Cancer Center/National Clinical Research Center for Cancer/ \\ Cancer Hospital, Chinese Academy of Medical Sciences and Peking Union Medical College, Panjiayuannanli No. 17, Chaoyang District, Beijing \\ 100021, China. Email: saintfisk@163.com.
}

\begin{abstract}
Background: The rate of unplanned return to the operation room (UROR) is an important index for the quality of surgeries. Study of the features and causes of patients who have suffered UROR is key to reduce the risk of it.

Methods: A retrospective, observational study was conducted among lung cancer patients who have received lung resections and UROR over a 5-year period. The causes, findings, procedures of UROR and recovery of patients were examined.

Results: Among the 23,345 lung cancer surgeries, 64 underwent UROR with the rate being $0.27 \%$. Lobectomy was performed in $78.1 \%$ of the patients. The most common indication was post-operative bleeding, responsible for $82.8 \%$ (53/64) of the cases. The median length of stay after the second surgery was 7 days and over $90 \%$ of the patients were discharged with proper recovery. The death rate within 90 days after return to operation room (OR) was 1.6\% (1/64). In the 53 cases caused by bleeding, 27 (50.9\%) occurred in surgical sites, with the raw surface of lymph node dissection being most frequently affected. Bleedings on incisions and unknown origin took up $11.3 \%$ and $37.7 \%$, respectively.

Conclusions: Bleeding is the most common indication which causes over $80 \%$ of UROR for lung cancer surgeries. Careful examination and complete hemostasis in surgery is key to reduce the risk of this unwanted complication.
\end{abstract}

Keywords: Unplanned return to operating room; lung cancer; surgery; bleeding

Submitted Aug 11, 2020. Accepted for publication Nov 04, 2020.

doi: $10.21037 /$ jtd-20-2651

View this article at: http://dx.doi.org/10.21037/jtd-20-2651

\section{Introduction}

Lung cancer is the most prevalent and deadly cancer worldwide (1). Surgical resection is one of the major treatment strategies of non-small cell lung cancer, especially for early stage diseases (2).

Quality of surgery has gained increasingly concern in recent years and unplanned return to the operation room (UROR) is one of the important indicators of the quality of surgery $(3,4)$. UROR is an adverse event which is often caused by major surgical related complications and which in turn, results in more complications, higher mortality rate, longer hospital stay, higher medical costs as well as patient suffering (5). Thus reduction of the rate of UROR is key for quality improvement of surgery.

Analysis of the etiology of UROR is critical to reduce the UROR rate. According to our knowledge, no study to date has investigated the causes and characteristics of UROR of 
Table 1 Demographic, clinical and pathological features of the patients $(\mathrm{n}=64)$

\begin{tabular}{lc}
\hline Feature & Number \\
\hline Age (year), average (SD) & $59.5(9.6)$ \\
Gender, (male), n (\%) & $51(79.7)$ \\
Tobacco use, (yes), n (\%) & $36(56.2)$ \\
Comorbidities, (yes), n (\%) & $19(29.7)$ \\
Past thoracic surgeries, (yes), n (\%) & $2(3.1)$ \\
Neoadjuvant therapy, (yes), n (\%) & $3(4.7)$ \\
Pathological subtype, n (\%) & \\
Adenocarcinoma & $37(57.8)$ \\
Squamous cell carcinoma & $22(34.4)$ \\
Large cell carcinoma & $2(3.1)$ \\
Metastatic cancer & $3(4.7)$ \\
Tumor size (cm), average (SD) & $2.8(1.9)$ \\
TNM stage*, n (\%) & $12(19.7)$ \\
I & $30(49.2)$ \\
II & $18(29.5)$ \\
\hline Unknown & \\
\hline calculated in primary lung cancer & \\
\hline
\end{tabular}

*, calculated in primary lung cancer patients $(n=61) . S D$, standard deviation; TNM, tumor, node, metastasis.

lung cancer patients. In order to reveal the causes of UROR after lung cancer surgeries and to provide insights for surgeons to prevent this unwanted event, we retrospectively examined all lung cancer patients who had an UROR in one admission over a 5 -year period in our center. We present the following article in accordance with the STROBE reporting checklist (available at http://dx. doi. org/10.21037/jtd-202651).

\section{Methods}

This was a single center, retrospective, observational study. The study was conducted in accordance with the Declaration of Helsinki (as revised in 2013). The study was approved by the medical ethics committee of the National Cancer Center, Cancer Hospital, Chinese Academy of Medical Sciences (CHCAMS) (No. 20/192-2388) and individual consent for this retrospective analysis was waived. Review of case notes and operation room (OR) system for lung cancer patients who had received surgery in National Cancer Center, CHCAMS from January 2014 to December 2018 was performed electronically. All patients who had received UROR in one admission with the primary surgery were included in the study.

Apart from the demographic, pathological, and surgical data of index surgeries, the detailed data of the unplanned reoperation of the patients was also collected by examining the medical records, pathological exams and surgical records. The tumor, node, metastasis (TNM) stage of the patients was defined according to the American Joint Committee on Cancer staging manual ( $8^{\text {th }}$ edition). Data for the reoperation included: the cause of UROR, the time between the index surgery and UROR, procedure performed in UROR and patients' recovery after UROR. In order to avoid potential bias, data collection was performed by two surgeons (JL \& JZ) independently. Disparities were discussed among group members till consensus was reached.

\section{Statistical analysis}

For data presentation and statistical comparison, quantitative variables were presented by mean with standard deviation (SD) and compared by Student's $t$-test. Categorical variables were presented by percentage and compared using chisquare or Fisher's exact tests. All tests were two-sided and statistical significance was defined as $\mathrm{P}<0.05$.

\section{Results}

\section{Demographic, clinical, and pathological features of the patients}

From January 2014 to December 2018, there were 23,345 lung cancer surgeries in our center, among which 64 patients had undergone UROR, yielding a UROR rate of $0.27 \%$.

The average age of the patients was $59.5 \pm 9.6$ (range, $30-77)$ years and the majority of them were male and smokers (Table 1). Comorbidities were observed in 19 (29.7\%) patients and hypertension was most frequent seen followed by diabetes mellitus (Table S1). Two patients had received thoracic surgeries previously. One had thoracotomy right upper lobectomy for lung cancer 8 years before and received thoracotomy wedge resection of a nodule on his right lower lobe this time. The other one had Sweet esophagectomy 4 years before and underwent thoracotomy anatomical sublobectomy of left upper lobe this time. Three patients were given two or three periods 
Table 2 Features of index surgery $(n=64)$

\begin{tabular}{|c|c|}
\hline Feature & Number \\
\hline Incision (VATS), n (\%) & $33(51.6)$ \\
\hline Conversion $^{\mathrm{a}}$, (yes), n (\%) & $2(6.1)$ \\
\hline Surgical site, (right), n (\%) & $36(56.2)$ \\
\hline \multicolumn{2}{|l|}{ Surgical procedure, n (\%) } \\
\hline Wedge resection & $6(9.4)$ \\
\hline Anatomical sublobectomy & $4(6.2)$ \\
\hline Lobectomy $^{\mathrm{b}}$ & $50(78.1)$ \\
\hline Pneumonectomy & $4(6.2)$ \\
\hline Surgery time (min), average (SD) & $148.4(59.6)$ \\
\hline Blood loss in operation $(\mathrm{mL})$, average (SD) & $85.3(185.7)$ \\
\hline Station of LND & $6.7(2.4)$ \\
\hline Number of LND & $20.1(11.3)$ \\
\hline \multicolumn{2}{|c|}{$\begin{array}{l}\text { a, calculated in patients with VATS }(n=33) ;{ }^{b} \text {, include } \\
\text { bilobectomy. VATS, video-assisted thoracoscopic surgery; SD } \\
\text { standard deviation; LND, lymph node dissection. }\end{array}$} \\
\hline
\end{tabular}

Table 3 Indications and post-operative considerations of UROR $(\mathrm{n}=64)$

\begin{tabular}{lc}
\hline Feature & Number \\
\hline Indications, $\mathrm{n}(\%)$ & $53(82.8)$ \\
Bleeding & $3(4.7)$ \\
Chylothorax & $3(4.7)$ \\
Chest cavity infection & $2(3.1)$ \\
Persistent air leak & $2(3.1)$ \\
Esophageal perforation & $1(1.6)$ \\
Thrombus of right lower extremity artery & $13(20.3)$ \\
Stay in ICU, (yes), $\mathrm{n}$ (\%) & \\
Outcome after UROR, $\mathrm{n}$ (\%) & $60(93.8)$ \\
Discharged after cure & $2(3.1)$ \\
Discharged without cure & $1(1.6)$ \\
Return to hospital within 30 days of discharge & $1(1.6)$ \\
Reoperation* & $1(1.6)$ \\
Death within 90 days* & $10.5(10.7)$ \\
Length of stay after UROR (day), average (SD) & \\
$*$
\end{tabular}

*, same patient. UROR, unplanned return to the operation room; ICU, intensive care unit; SD, standard deviation. of neoadjuvant chemotherapy. Histologic subtypes included adenocarcinoma in 37 , squamous cell carcinoma in 22 , large cell carcinoma in two and metastatic tumors in three (Table 1). The mean diameter of the tumors was $2.8 \pm$ 1.9 (range, 0.5-9) $\mathrm{cm}$ and pathological TNM stage of the patients is also shown in Table 1.

\section{Characteristics of index surgery}

We then analyzed the characteristics of the index surgeries of the patients. Minimally invasive surgery was performed in $33(51.6 \%)$ patients with the rate of conversion to open being $6.1 \%(2 / 33)$ (Table 2). The majority of the patients had lobectomy $(78.1 \%)$ and the percentage of patients receiving wedge resection, anatomical sublobectomy, and pneumonectomy were $9.4 \%, 6.2 \%$, and $6.2 \%$, respectively. The mean duration of surgery was $148.4 \pm 59.6$ (range, 40-300) min with an average intraoperative blood loss of $85.3 \pm 185.7$ (range, $5-1,200$ ) $\mathrm{mL}$. The mean intraoperative blood loss for the non-UROR patients was $83.7 \pm 177.6$ (range, $5-1,500) \mathrm{mL}$, which was similar. Averagely, 6.7 \pm 2.4 (range, 0-11) stations of 20.1 \pm 11.3 (range, 0-47) lymph nodes had been dissected during the surgeries (Table 2).

\section{Considerations of UROR}

Next, the detailed data of UROR for all the patients was evaluated. The most common cause for UROR was bleeding, which accounts for over $80 \%$ of the cases. Other indications included chylothorax, chest cavity infection, persistent air leak, esophageal perforation, and lower extremity artery thrombus (Table 3). Follow-up for shortterm results were done till 60 days after discharge. After UROR, $13(20.3 \%)$ patients stayed in intensive care unit (ICU) and the average length of hospital stay after UROR was $10.5 \pm 10.7$ (range, 4-82) days. Over $90 \%(60 / 64)$ of the patients recovered properly and were discharged within 30 days after UROR (Table 3). Two patients were transferred to community medical centers for recovery. One patient was readmitted on the $26^{\text {th }}$ day after discharge for recurrent chest cavity infection. There was one case that underwent reoperation after UROR and died in hospital 27 days after, resulting in a perioperative death rate of $1.6 \%$ (Table 3 ). This was significantly higher than the non UROR patients, which was $0.11 \%(\mathrm{P}<0.001)$. The surgical procedures of UROR for different causes were presented in Table 4. 
Table 4 Procedures of UROR for different indications

\begin{tabular}{ll}
\hline Indication & Procedure \\
\hline Bleeding $(n=53)$ & Inspection, washing and hemostasis + lobectomy of congested lobe in two cases \\
Chylothorax $(n=3)$ & Ligation of thoracic duct \\
Chest cavity infection $(n=3)$ & Debridement and drainage \\
Persistent air leak $(n=2)$ & Wedge resection of ruptured bulla \\
Esophageal perforation $(n=2)$ & Repair of perforation and drainage \\
Artery thrombus $(n=1)$ & Interventional removal of tumorous embolus \\
\hline
\end{tabular}

UROR, unplanned return to the operation room.

Table 5 Characteristics of UROR caused by bleeding $(\mathrm{n}=53)$

\begin{tabular}{|c|c|}
\hline Feature & Number \\
\hline Time after initial surgery (hour), median (IQR) & $7.8(19.0)$ \\
\hline $\begin{array}{l}\text { Drainage volume before UROR }(\mathrm{mL}) \text {, } \\
\text { median (IQR) }\end{array}$ & $1,050.0(600.0)$ \\
\hline Estimated blood loss (mL), median (IQR) & $2,100.0(1,000.0)$ \\
\hline \multicolumn{2}{|l|}{ Bleeding site, $\mathrm{n}(\%)$} \\
\hline Unfound & $20(37.7)$ \\
\hline Incision & $6(11.3)$ \\
\hline \multicolumn{2}{|l|}{ Surgical sites } \\
\hline Raw surface of mediastinal LND & $6(11.3)$ \\
\hline Resection margin of lung & $5(9.4)$ \\
\hline Raw surface inferior pulmonary ligament & $5(9.4)$ \\
\hline Parietal pleura & $4(7.5)$ \\
\hline Pulmonary vessels & $3(5.7)$ \\
\hline Bronchus stump & $3(5.7)$ \\
\hline Congestion of wedge resected lobe & $2(3.8)$ \\
\hline Blood transfusion $(\mathrm{mL})$, median [IQR] & $1,200[900]$ \\
\hline Stay in ICU, (yes), n (\%) & $11(20.8)$ \\
\hline Length of stay after UROR (day), median [IQR] & 7 [3] \\
\hline
\end{tabular}

\section{Features of UROR caused by bleeding}

In order for better understanding of the most common cause of UROR for lung cancer surgery, we further examined the surgically related characteristics of the 53 UROR cases that were caused by bleeding. The median time interval between the index surgeries was 7.8 hours with a median drainage volume of $1,050.0 \mathrm{~mL}$ at the time of UROR. A median blood loss of 2,100 mL was observed and the patients needed a median 1,200 $\mathrm{mL}$ of blood transfusion (Table 5). As to the bleeding sites that caused the UROR, over half $(27 / 53,50.9 \%)$ of the bleeding occurred in surgical sites in thoracic cavity, among which raw surface of mediastinal lymph node dissection (LND) was most common. Other sites included pulmonary resection margin, inferior pulmonary ligament, parietal pleura, pulmonary vessels, and bronchial artery at bronchus stumps. Two patients that underwent wedge resection at the index surgery were found to have congestion on the resected lobe during UROR and received lobectomy of the affected lobe. Bleeding was discovered on the incision in $11.3 \%$ of the cases and in over one-third of the patients, no bleeding site was found even after careful and thorough inspection. After UROR, around one-fifth of the patients needed to stay in ICU and the median length of hospital stay was 7 days (Table 5).

\section{Discussion}

In the current study, we analyzed the characteristics of 64 lung cancer patients who had undergone UROR in a 5 -year period. Our results showed that bleeding was the most common course of UROR for lung cancer surgery, responsible for $82.8 \%$ of the cases. About half of the bleeding happened in surgical sites, $11.3 \%$ were in incisions, and $37.7 \%$ were not found. Over $90 \%$ of the patients recovered properly with the median length of stay after UROR being 7 days.

UROR has been a critical criteria to measure the quality of surgeries and summary and examinations of features of UROR could provide fundamental insights to improve 
the level of surgical treatment $(5,6)$. According to our knowledge, this is the first study evaluating the clinical characteristics, causes, and in-operation findings of UROR for lung cancer patients.

Post-operative bleeding is an urgent and life-threatening complication that often needs emergent surgical treatment. It is also one of the major indications that causes UROR in different surgeries $(7,8)$. Our study showed that bleeding accounted for over $80 \%$ of the UROR for lung cancer surgeries. Understanding of the causes for UROR is fundamental for the reduction of this unwanted complication. Thus our findings are important for they give thoracic surgeons a reminder that careful examination for potential bleeding sites at the end of surgeries could reduce the risk of UROR in a great measure.

Our study also revealed that nearly half of the bleeding $(26 / 53,49.0 \%)$ did not happen in the in-thoracic surgical sites. As to the $20(37.7 \%)$ cases with unidentified bleeding site, it is suspected that some of them might have bleeding in incisions, because when we take the same incisions in UROR as the initial procedure, bleeding on the incisions become hard to be discovered (9). These results indicate that incisions should also be checked with equal care as the surgical sites before finishing surgeries.

We have observed a substantial variation of blood loss for the patients during the index surgery $(5-1,200 \mathrm{~mL})$. This is owing to two cases of high-volume blood loss (900 and 1,200 $\mathrm{mL}$, respectively). One patient had hemorrhage due to anatomical variation of pulmonary artery while the other due to intensive adhesion. The other 62 patients had intraoperative blood loss less than or equal to $200 \mathrm{~mL}$.

The current study only analyzed the characteristics of lung cancer patients who have suffered UROR. Thus our manuscript has limitations in that the risk factors associated with UROR were not assessed. Also, our results still need verification by multi-central studies.

Although our manuscript is a single center, retrospective study, yet the 64 patients was based on a large cohort of 23,345 lung cancer patients over a 5-year period. Plus, the National Cancer Center, CHCAMS in which the study was conducted, is a national wide, large volume center in China. The patients are from different areas all around China (10). Thus the results of our study have robust representativeness.

\section{Conclusions}

In conclusion, our study has revealed that post-operative bleeding is the most common cause of UROR for lung cancer surgeries, followed by chylothorax and chest cavity infection. About half of the bleeding occurred in surgical sites with the other half in incisions or unknown origin. The risk factors of UROR for lung cancer surgeries needs further studies.

\section{Acknowledgments}

Funding: This work was supported by the Beijing Hope Run Foundation (LC2017B24), Fundamental Research Funds for the Central Universities (2017PT32001), and the CAMS Innovation Fund for Medical Sciences (2017-I2M$1-005)$.

\section{Footnote}

Reporting checklist: The authors have completed the STROBE reporting checklist. Available at http://dx. doi. org/10. 21037/jtd-20-2651

Data Sharing Statement: Available at http://dx. doi. org/10. 21037/jtd-20-2651

Conflicts of Interest: All authors have completed the ICMJE uniform disclosure form (available at http://dx. doi. org/10. 21037/jtd-20-2651). The authors have no conflicts of interest to declare.

Etbical Statement: The authors are accountable for all aspects of the work in ensuring that questions related to the accuracy or integrity of any part of the work are appropriately investigated and resolved. The study was conducted in accordance with the Declaration of Helsinki (as revised in 2013). The study was approved by the medical ethics committee of the National Cancer Center, Cancer Hospital, Chinese Academy of Medical Sciences (CHCAMS) (No. 20/192-2388) and individual consent for this retrospective analysis was waived.

Open Access Statement: This is an Open Access article distributed in accordance with the Creative Commons Attribution-NonCommercial-NoDerivs 4.0 International License (CC BY-NC-ND 4.0), which permits the noncommercial replication and distribution of the article with the strict proviso that no changes or edits are made and the original work is properly cited (including links to both the formal publication through the relevant DOI and the license). See: https://creativecommons.org/licenses/by-nc-nd/4.0/. 


\section{References}

1. Bray F, Ferlay J, Soerjomataram I, et al. Global cancer statistics 2018: GLOBOCAN estimates of incidence and mortality worldwide for 36 cancers in 185 countries. CA Cancer J Clin 2018;68:394-424.

2. Ettinger DS, Wood DE, Aggarwal C, et al. NCCN guidelines insights: non-small cell lung cancer, version 1.2020. J Natl Compr Canc Netw 2019;17:1464-72.

3. Birkmeyer JD, Hamby LS, Birkmeyer CM, et al. Is unplanned return to the operating room a useful quality indicator in general surgery? Arch Surg 2001;136:405-11.

4. Kroon HM, Breslau PJ, Lardenoye JW. Can the incidence of unplanned reoperations be used as an indicator of quality of care in surgery? Am J Med Qual 2007;22:198-202.

5. Lightner AL, Glasgow AE, Habermann EB, et al. Returns to operating room after colon and rectal surgery in a tertiary care academic medical center: a valid measure of surgical quality? J Gastrointest Surg 2017;21:1048-54.

6. Lin Y, Meguid RA, Hosokawa PW, et al. An institutional

Cite this article as: Li J, Xue Q, Gao Y, Mao Y, Zhao J, Gao S. Bleeding is the most common cause of unplanned return to operating room after lung cancer surgeries. J Thorac Dis 2020;12(12):7266-7271. doi: 10.21037/jtd-20-2651 analysis of unplanned return to the operating room to identify areas for quality improvement. Am J Surg 2017;214:1-6.

7. Mahfouz I, Asali F, Wiltshire R, et al. Unplanned return to the operating theatre in gynaecology: five years' experience. Eur J Obstet Gynecol Reprod Biol 2011;157:222-5.

8. Wang J, Xu Y, Liu R, et al. Analysis of unplanned return to the operating room within 30 days of initial neurosurgery: a 3-year experience at a single center. World Neurosurg 2018;118:e766-71.

9. Li J, Qiu B, Scarci M, et al. Uniportal video-assisted thoracic surgery could reduce postoperative thorax drainage for lung cancer patients. Thorac Cancer 2019;10:1334-9.

10. Li J, Chen Z, Tian L, et al. LncRNA profile study reveals a three-lncRNA signature associated with the survival of patients with oesophageal squamous cell carcinoma. Gut 2014;63:1700-10. 


\section{Supplementary}

Table S1 Preoperative comorbidities ( $\mathrm{n}=19)$

\begin{tabular}{lc}
\hline Comorbidity & Number \\
\hline Hypertension & 14 \\
Diabetes mellitus & 5 \\
Coronary artery disease & 2 \\
Tuberculosis & 2 \\
Hyperthyroidism & 1 \\
Total ${ }^{*}, \mathrm{n}(\%)$ & $19(29.7)$ \\
\hline
\end{tabular}

*, includes four patients with more than one comorbidity. 